\title{
Occupational Health
}

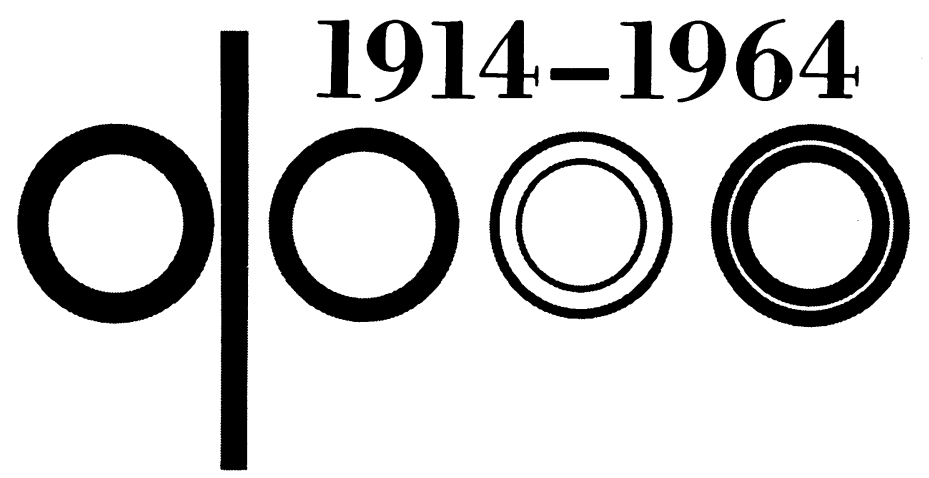

0 $\mathrm{NE}$ of man's greatest burdens is his apparent inability to free himself completely from the shackles of disease. When the illness stems from man's efforts to wrest a living from a hostile environment, the tragedy is compounded.

The occupational health area of public health work has provided a bulwark against this tyranny of the past. A synergism of science and philosophy, occupational health has sought the maximum fulfillment for man through his work. At the least, it holds forth the goal of a harmonious work environment free from harmful exposures and conducive to optimal health. Its fuller potential can only be sighted as our society advances in self-understanding.

In a movement only 50 years old-marked by the creation in 1914 in the Public Health Service of a unit dedicated solely to the protection of the health of American workers-major emphasis has necessarily been on the more basic problem of cause and effect. Early studies by the Division of Occupational Health identified and enumerated the sacrifices exacted by a newly developing technology. Eventually, out of the crucible of human suffering, laws and practices evolved to safeguard the dignity and welfare of the nation's workers.

Some might, with good reason, characterize the past half-century as the golden age of occupational health in the United States. Indeed, as that noted scientist Dr. Rene Dubos has observed: "It is a remarkable fact that the greatest strides in health improvement have been achieved in the field of diseases that responded to social and economic reforms after industrialization." Others hold out the hope that, while occupational health has achieved its most spectacular triumphs, the richest, less accessible lodes remain to be mined. Growing recognition of the interplay of multiple factors in disease causation, the as yet undefined role of the work environment in the chronic degenerative diseases, and the advancement of all knowledge through space research are pointed to as promising horizons.

Not all facets of a field as complex as occupational health could, of course, be covered in the nine papers on the following pages. We have attempted to concentrate on a few aspects that may hold the greatest interest.

Some of the gains of the past half-century and expectations of the future are traced here, together with the status of occupational health in official agencies, growth of services in industry, development of nursing in occupational health, use of morbidity and mortality evaluations, the complementary relationship of occupational health to environmental health, some newer problems of mental health, and diseases of white collar workers. We hope that they will provide some perspective on the tasks ahead and how they can be accomplished most effectively.-Harry Heimann, M.D., chief, Division of Occupational Health, Public Health Service. 